\title{
Delayed membranous cranial ossification
}

INSERM

\section{Source}

INSERM. (1999). Orphanet: an online rare disease and orphan drug data base. Delayed membranous cranial ossification. ORPHA:3034

Delayed membranous cranial ossification is a rare, genetic primary bone dysplasia characterized by absent ossification of calvarial bones at birth and characteristic facial dysmorphisms (frontal bossing, hypertelorism, downward-slanting palpebral fissures, proptosis, flat nasal bridge, low-set ears, midface retrusion). Patients present a soft skull at birth which, over time, prog ressively ossifies and in adulthood typically results in a deformed skull (with brachycephaly and prominent occiput). No other skeletal abnormalities are associated and patients have normal cognitive and motor development. 